\title{
RESPOSTAS FISIOLÓGICAS DE DIFERENTES CLONES DE EUCALIPTO SOB DIFERENTES REGIMES DE IRRIGAÇÃO ${ }^{1}$
}

Ana Lídia Tonani Tolfo Vellini², Nádia Figueiredo de Paula ${ }^{3}$, Pedro Luis da Costa Aguiar Alves ${ }^{4}$, Luiz Carlos Pavani ${ }^{4}$, Cesar Augusto Valencise Bonine ${ }^{5}$, Edimar Aparecido Scarpinati ${ }^{5}$ e Rinaldo Cesar de Paula ${ }^{4}$

\begin{abstract}
RESUMO - O objetivo deste trabalho foi avaliar o desempenho de clones de Eucalyptus spp. em diferentes regimes hídricos, em casa de vegetação, visando subsidiar trabalhos de melhoramento quanto à tolerância ao estresse hídrico. O experimento foi conduzido por 73 dias, em delineamento em blocos casualizados, no esquema fatorial 18 x 4 (18 clones e quatro regimes de irrigação: diária e a cada dois, quatro e seis dias), com quatro repetições. Avaliou-se o incremento relativo em altura, diâmetro do coleto, número de folhas, área foliar, matéria seca de folhas, de caule e de raízes, razão raiz/parte aérea, taxa líquida de fotossíntese, condutância estomática, transpiração e potencial hídrico foliar. As avaliações fisiológicas foram realizadas um dia antes e um dia depois da irrigação de cada tratamento. Todas as características apresentaram diferenças significativas tanto entre os genótipos quanto entre os regimes hídricos. As estimativas do coeficiente de determinação genotípico apresentaram valores acima de 0,86 quanto às características de crescimento e entre 0,46 e 0,84 com relação às fisiológicas. Em geral, os clones apresentaram reduções nas características analisadas à medida que a freqüência de irrigação diminuiu, mas em proporções variáveis entre eles. Foi possível identificar material genético promissor para trabalhos de melhoramento visando à tolerância ao estresse hídrico.
\end{abstract}

Palavras-chave: Estresse hídrico, parâmetros fisiológicos e Eucalyptus spp

\section{GROWTH AND PHYSIOLOGICAL TRAITS OF EUCALYPT CLONES UNDER DIFFERENTS WATER REGIMES}

\begin{abstract}
The aims of this work were to evaluate the growth and physiological traits of eucalypt clones submitted to four irrigation regimes, in a greenhouse, and to subsidiary breeding programs to resistance to water stress. The experiment was carried out in a randomized block design, and a factorial scheme 18 x 4 (18 clones and four irrigation regimes: daily; every two days; every four days; every six days) with four replications during 73 days. It was evaluated the relative growth rate at height, root collar diameter, number of leaves, leaf area, dry matter of the leaves, stem and roots, the root-shoot ratio, the net photosynthesis, stomatal conductance, transpiration and leaf water potential. The physiological evaluations were performed one day before and one day after the irrigation in each treatment. All the evaluated characters presented significant difference among genotypes and water regimes. The estimates of genotypic determination coefficient presented values over 0.86 for growth traits and between 0.46 and 0.84 for physiological ones. The genotypes generally presented reduction in their traits as the frequency of irrigation was decreased, although in variable proportions among them. It was possible to identify promising genotypes for breeding aiming the resistance to drought stress.
\end{abstract}

Keywords: Water stress, physiological parameters and Eucalyptus spp.

\footnotetext{
${ }^{1}$ Recebido em 11.05.2007 e aceito para publicação em 19.05.2008.

${ }^{2}$ Centro Universitário de Votuporanga, Votuporanga-SP. E-mail: <alttolfo@globo.com>.

${ }^{3}$ Doutoranda da UFSCar, PPG-ERN, São Carlos-SP

${ }^{4}$ Departamento de Biologia Aplicada à Agropecuária - F.C.A.V./UNESP. V Jaboticabal, SP. E.mail:<rcpaula@fcav.unesp.br> .

${ }^{5}$ Votorantim Celulose e Papel, Rodovia SP 255, km 41,240 14210-000 - Luis Antonio, SP. E-mail: <edimar.scarpinati@vcp.com.br>.
} 


\section{INTRODUÇÃO}

A busca por maior produtividade no setor florestal tem demandado pesquisas à procura de materiais genéticos mais produtivos e adaptados às diferentes condições ambientais. Freqüentemente, as plantas se encontram sob condições desfavoráveis ao seu desenvolvimento (CAMBRAIA, 2005), sendo que a intensidade e os efeitos prejudiciais às mesmas dependerão da duração (FLEXAS et al., 1999) e da severidade dessas condições (FLEXAS et al., 2002), do estádio de desenvolvimento e do genótipo utilizado (TARDIEU e SIMONNEAU, 1998), dentre outros fatores.

Dos fatores ambientais que podem ocasionar estresse em uma planta tais como radiação solar, disponibilidade hídrica e temperatura (SOUZA et al., 2006), a água é o mais limitante para a sustentabilidade dos sistemas agrícolas (PAIVA et al., 2005), pois afeta as relações hídricas, alterando o metabolismo nas plantas, causando grandes perdas em produtividade (NOGUEIRA et al., 2001). Segundo Flexas et al. (2002), o estresse hídrico é a principal causa de perdas na produtividade agronômica e florestal.

Como resposta a deficiência hídrica, as plantas passam por mudanças fundamentais na relação da célula com a água e nos seus processos fisiológicos (PIMENTEL, 2005) e morfológicos (REIS et al., 1988; CHAVES et al., 2004), influenciando a sua capacidade de tolerar as condições adversas do meio. Por conseguinte, há restrição ao acúmulo de massa (SILVA, 1998), prejudicando tanto no crescimento inicial das plantas como nos estádios mais tardios, limitando a dimensão das folhas individuais, o número de folhas, o número e taxas de crescimento dos ramos e o crescimento do caule (OSÓRIO et al., 1998)

O estresse hídrico por escassez de água ocorre quando a baixa disponibilidade de água afeta os processos fisiológicos (SILVA, 1998), como transpiração, fotossíntese, abertura estomática (FLEXAS et al., 2002; CHAVES et al., 2003; WRIGHT et al., 2004), produção de ácido abscísico (TAYLOR et al., 2000; SEKI et al., 2007) e ajuste osmótico (BRAY, 1997; CALLISTER et al., 2006).

De acordo com Nogueira et al. (2005), o efeito da deficiência hídrica sobre as plantas é complexo, não havendo um mecanismo universal de resistência à seca, pois as plantas respondem através de vários processos adaptativos à escassez de água como, por exemplo, através da capacidade de reduzir o potencial hídrico, aliada a adaptações morfológicas, anatômicas e fisiológicas. Ainda, segundo esses autores, embora esses processos de resistência à seca sejam avaliados muitas vezes isoladamente, as espécies utilizam mecanismos associados para a sua sobrevivência em condições desfavoráveis de disponibilidade de água.

Muitas plantas podem se aclimatar à falta de água através de ajustamento osmótico, que possibilita a manutenção da turgescência celular e, conseqüentemente, o crescimento em baixos potenciais de água nas folhas (NOGUEIRA et al., 2001; ARRIEL, 2004; CARVALHO, 2005). Assim, a identificação e a compreensão dos mecanismos de resistência à seca são fundamentais no desenvolvimento de cultivares comerciais mais resistentes ao estresse hídrico (NEPOMUCENO et al., 2001).

A cultura do Eucalyptus se encontra espalhada por quase todo o território nacional, sendo que grande parte da área de cultivo apresenta limitações ao desenvolvimento das plantas como diversos níveis de estresse hídrico. Desta forma é difícil a escolha de indivíduos adaptados, tornando-se necessário identificar os materiais mais promissores para cada situação (STAPE et al., 2004). A identificação destes materiais pode se dar através do emprego de características fisiológicas adequadas para seleção, beneficiando o melhoramento genético (NOGUEIRA et al., 2001), buscando equilíbrio entre os caracteres que otimizam o crescimento com aqueles que conferem maior resistência à seca (PITA et al., 2005).

O presente trabalho teve por objetivo avaliar as respostas fisiológicas de diferentes genótipos de Eucalyptus spp., cultivados em diferentes regimes de irrigação em casa de vegetação.

\section{MATERIAL E MÉTODOS}

Foram usados clones de 18 genótipos de eucalipto, doravante denominados clones, da Votorantim Celulose e Papel S.A., multiplicados pelo método de miniestaquia, em tubetes de polipropileno com capacidade para 60 cm3 de substrato. Destes, o genótipo 2 é um clone de E. saligna, o 6 é um clone de E. grandis e o genótipo 15, um clone de E. urophylla, os demais são clones de híbridos entre Eucalyptus grandis x E. urophylla. 
As mudas, com cerca de 70 dias de idade, foram transplantadas para vasos pretos, de plástico, preenchidos com $3 \mathrm{~kg}$ de Neossolo Quartzarênico previamente seco em estufa de circulação forçada de ar $\left(70{ }^{\circ} \mathrm{C}\right)$, passado em peneira de $0,4 \mathrm{~cm}$ e adubado com formulação NPK (4-30-16) em quantidade suficiente para fornecer $150 \mathrm{mg} \mathrm{dm}^{-3} \mathrm{de} \mathrm{K}$. Em seguida, foi adicionado a cada vaso quantidade de água suficiente para elevar a umidade para $21 \%$ em volume (60\% da capacidade de campo). Durante quatro dias, visando garantir a sobrevivência das mudas, todos os vasos foram mantidos com $21 \%$ de umidade, por monitoramento da umidade do substrato com uso do TDR Hydrosense System (Campbell Scientific, modelo CS620).

Após o período de aclimatação das mudas, essas foram submetidas a quatro regimes de irrigação: RID - irrigação diária; RI2 - irrigação a cada dois dias; RI4 - irrigação a cada quatro dias e RI6 - irrigação a cada seis dias (estabelecido em testes preliminares). Esses regimes foram monitorados com o uso do TDR Hydrosense System CS620, repondo-se água em função da necessidade de cada vaso para atingir os $21 \%$ de umidade do substrato.

Aos 45 dias após o início dos regimes de irrigação, as plantas receberam adubação de cobertura, aplicandose via solução aquosa $30 \mathrm{mg} \mathrm{dm}^{-3} \mathrm{~N}$, na forma de sulfato de amônio.

Na implantação e ao final do experimento, após 73 dias do início da aplicação dos regimes de irrigação, foram feitas avaliações de altura, diâmetro do coleto, número de folhas, área foliar (com o uso de um medidor de área foliar LICOR, modelo LI 3000A), massa seca de folhas, de caule e de raízes (determinadas após secagem dos materiais em estufa com circulação forçada de ar a $70{ }^{\circ} \mathrm{C}$ ) e razão raiz/parte aérea.

Um dia antes e um dia depois da irrigação em cada um dos tratamentos, foram avaliadas as seguintes características: taxas de fotossíntese líquida $(A)$, condutância estomática ( $g s)$ e transpiração $(E)$, usando um analisador de gás por infravermelho portátil (LICOR, modelo LI6400), acoplado a uma fonte de luz artificial (LED 640002B). As medidas de $A$, gs e $E$ foram feitas sob concentração de $\mathrm{CO}_{2}$ ambiente (370 $\pm 10 \mathrm{ì} \mathrm{mol} \mathrm{m} \mathrm{m}^{-2} \mathrm{~s}^{-1}$ ), fluxo de fótons fotossinteticamente ativo de 900 ì mol m-2 $\mathrm{m}^{-1} \mathrm{e}$ temperatura da folha mantida a $26^{\circ} \mathrm{C}$. As medições foram feitas nos períodos compreendidos entre 8:0010:00h, 10:00-12:00h e 13:30-15:30h. Estas avaliações foram realizadas em três repetições, na terceira folha totalmente expandida, contada a partir do ápice da planta. Também, antes da última irrigação, foi determinado o potencial hídrico foliar (Øf) por meio de uma bomba de pressão (SCHOLANDER et al., 1965), empregando-se duas repetições para cada tratamento.

As análises estatísticas foram realizadas segundo o delineamento de blocos casualizados, no esquema fatorial 18 x 4 (18 genótipos e 4 regimes de irrigação), com quatro repetições para as características de crescimento, três para as fisiológicas e duas para o potencial hídrico. Como os genótipos (clones) apresentavam desenvolvimento diferenciado na época da instalação do experimento, os dados de altura, diâmetro do coleto, número de folhas, área foliar e matéria seca de folhas, de raízes e de caule foram analisados considerando o incremento relativo (IR).

As análises de variância e as estimativas dos parâmetros genéticos foram processadas no programa Genes (CRUZ, 2001), considerando os efeitos de genótipos (clones) e regime de irrigação como fixos. As médias de clones e de regimes de irrigação foram comparadas pelo teste de Scott-Knott a 5\% de probabilidade.

\section{RESULTADOS E DISCUSSÃO}

Houve diferenças significativas ( $\mathrm{p}<0,01$ ou $\mathrm{p}$ $<0,05$ ) entre os genótipos (clones) e entre os regimes hídricos para todas as características avaliadas. A interação clones $\mathrm{x}$ regimes hídricos foi significativa ( $\mathrm{p}<0,01$ ou $\mathrm{p}<0,05$ ) apenas para os incrementos relativos em área foliar (IR-AF) e em massa seca de raízes (IR-MSR) e para transpiração antes da irrigação (E-AI) (Tabelas 1 e 2).

Os coeficientes de variação experimental (CV) foram altos para todas as características de crescimento (Tabela 1), exceto para os incrementos relativos em altura (IR-ALT) e em matéria seca de caule (IR-MSC), que apresentaram valores de média magnitude, segundo a classificação de Gomes (2000). Para os parâmetros fisiológicos (Tabela 2), os valores de CV foram médios (10-20\%) para potencial hídrico foliar (?f) e altos (20-30\%) para taxa de fotossíntese (A), e muito altos (> 30\%) para condutância estomática ( $g s)$ e transpiração $(E)$.

R. Árvore, Viçosa-MG, v.32, n.4, p.651-663, 2008 


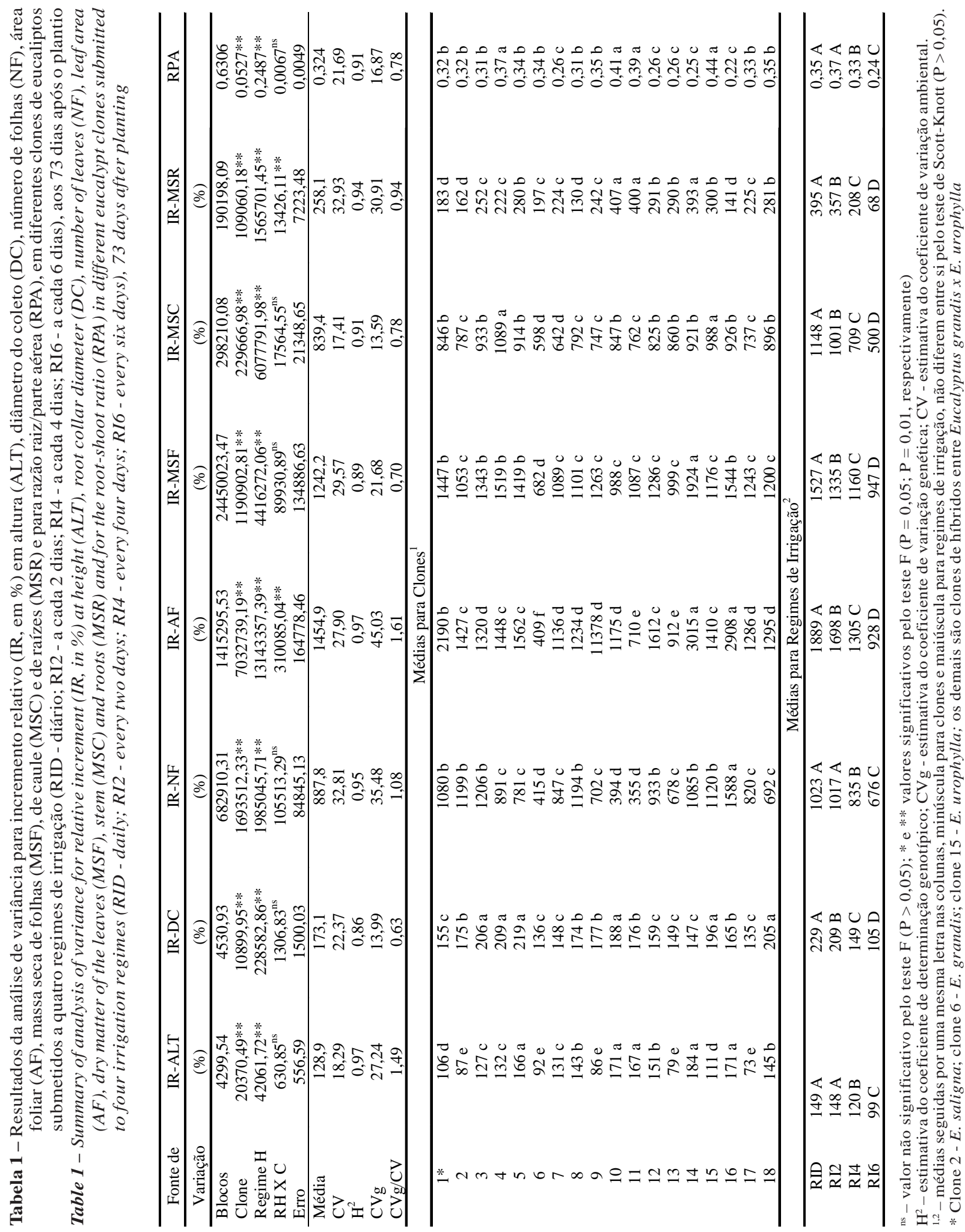

R. Árvore, Viçosa-MG, v.32, n.4, p.651-663, 2008 


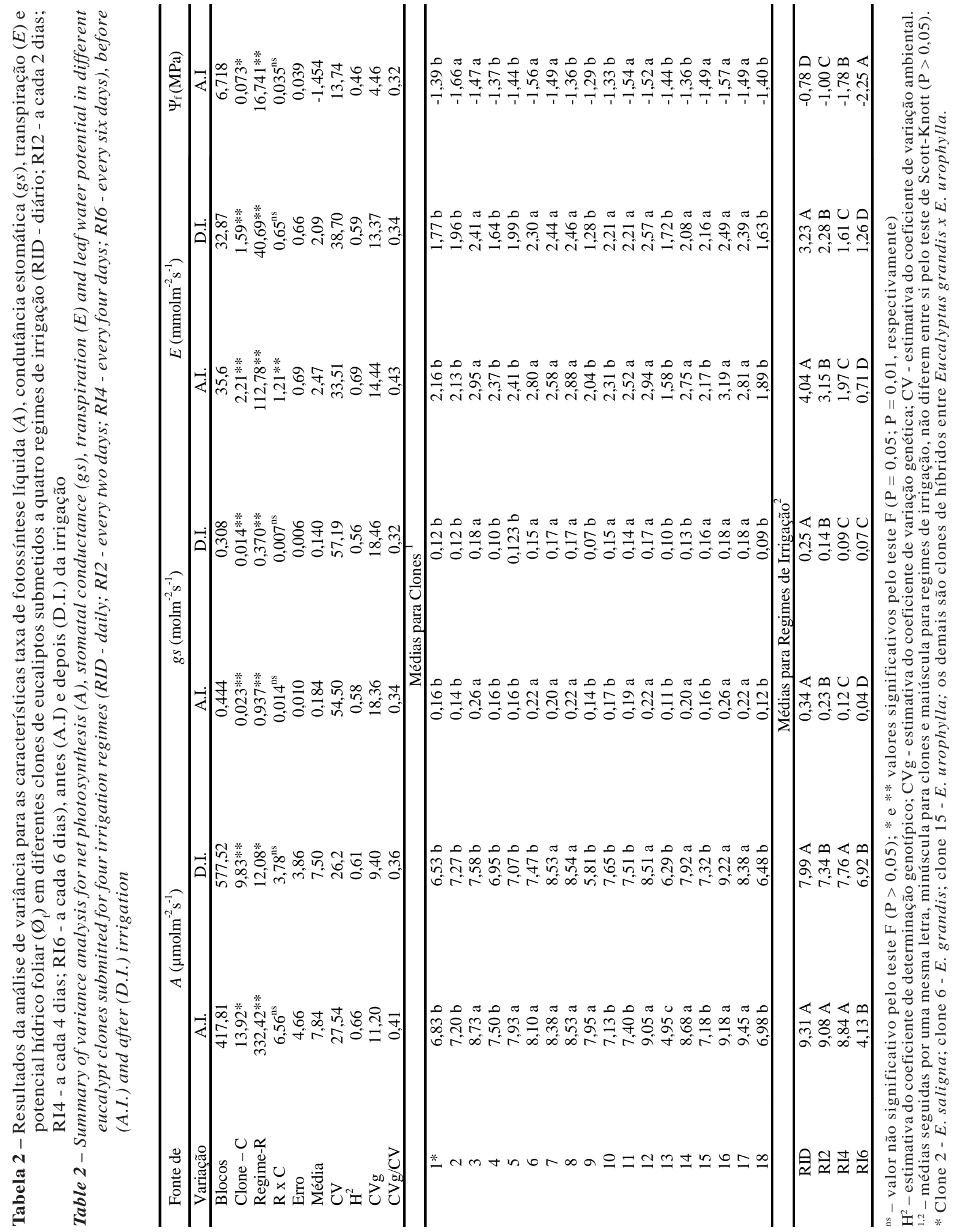

R. Árvore, Viçosa-MG, v.32, n.4, p.651-663, 2008 
A relação entre o coeficiente de variação genética e experimental (CVg/CV) foi superior a 1,0 para a IR-ALT, IR-AF e para o incremento relativo em número de folhas (IR-NF), e inferior a 1,0 para as demais características (Tabelas 1 e 2). De acordo com Vencovsky (1987), a relação CVg/CV é um dos indicativos das possibilidades de ganhos com a seleção; quando essa razão é maior que um, indica condição favorável à seleção, pois a variação genética supera a ambiental.

As estimativas do coeficiente de determinação genotípico (H2), entre as características de crescimento (Tabela 1 ), variaram de 0,86 para o incremento relativo em diâmetro do coleto (IR-DC) a 0,97 para IR-ALT e IR-AF, indicando alto controle genético sobre as mesmas. Resultados semelhantes foram encontrados por Arriel (2004), estudando crescimento de mudas de Cnidosculus phyllacanthus Pax e K. Hoffm. (faveleira) submetidas a três regimes hídricos. Para os parâmetros fisiológicos (Tabela 2), as estimativas de $\mathrm{H}^{2}$ foram de alta magnitude $(>0,61)$ para A antes e depois da irrigação, e para $E$ antes da irrigação, enquanto as demais características apresentaram moderado controle genético $\left(0,46<\mathrm{H}^{2}\right.$ $>0,59)$.

Os genótipos 10 e 14 encontram-se entre os melhores para a maioria das características de crescimento; já o genótipo 6 apresentou desempenho inferior para os incrementos relativos em altura, diâmetro do coleto, numero de folhas, área foliar e massa seca de folhas e de caule (Tabela 1$)$.

Quanto aos regimes de irrigação, os melhores desempenhos foram observados no regime de irrigação diária (RID) e os menores no regime de irrigação a cada seis dias (RI6). Este resultado está de acordo com Flexas et al. (2002) que afirmam que a baixa disponibilidade hídrica limita o crescimento e a produção. Ngugi et al. (2003) obtiveram maior área foliar e maior biomassa em mudas irrigadas de E. cloeziana e E. argopholia e Costa e Silva et al. (2004) observaram maiores valores de área foliar, comprimento de raiz e número de ramificações em mudas irrigadas de clones de E. globulus.

Em geral, o IR-AF foi maior nos regimes RID e RI2, comparativamente a RI4 e RI6 (Tabela 3). Nos quatro regimes hídricos, os clones 14 e 16 apresentaram maiores índices de crescimento relativo em área foliar, enquanto os clones 6 e 11 apresentaram os menores valores. Também, houve tendência de menor diferenciação entre genótipos à medida que a disponibilidade hídrica diminuiu, com a formação de menor número de grupos. Os maiores índices de crescimento em área foliar observados paras os clones 16 e 14, independentemente do regime hídrico, possibilitou aos mesmos, bom crescimento tanto em altura como em diâmetro, e consequentemente, boa produção de massa seca. Desta forma, esses clones são capazes de usar a água de forma mais eficiente que os demais, possibilitando o maior crescimento mesmo sob menor disponibilidade hídrica. Por outro lado, o clone 6 caracteriza-se como sendo de baixo investimento em área foliar, mesmo sob condições adequadas de disponibilidade de água, o que reflete no seu menor crescimento e produção de biomassa, comparativamente aos demais clones.

O índice de crescimento em massa seca de raízes (IR-MSR) foi maior no regime diário (RID) e a cada dois dias de irrigação (RI2), diminuindo nos outros dois regimes de irrigação. À semelhança do que ocorreu com área foliar, a diferenciação entre os clones foi menor à medida que a disponibilidade de água diminuiu para as plantas, havendo a formação de maior numero de grupos de genótipos no regime diário de irrigação, ao passo não foi observada diferença entre os genótipos no regime de irrigação a cada 6 dias. Os clones 10 e 14, independentemente do regime hídrico apresentaram os maiores IR-MSR, já os clones 8, 16, 2, 6 e 1 apresentaram os menores. Maior crescimento radicular em condições de baixa disponibilidade hídrica é uma estratégia de tolerância ao déficit hídrico, conforme relatado por Reis et al. (2006) que observaram que clones de híbridos de eucalipto com intenso crescimento do sistema radicular apresentaram menor sensibilidade à deficiência hídrica. Contudo, condições muito limitantes ao crescimento das plantas, podem fazer com que os materiais genéticos tenham desempenho semelhante, não possibilitando a identificação de materiais promissores. Desta foram, pode-se considerar que o RI6 tenha sido muito severo às plantas, e que os regimes RI2 e RI4 constituam condições mais adequadas para a identificação de genótipos promissores para plantio em locais com restrição hídrica. 


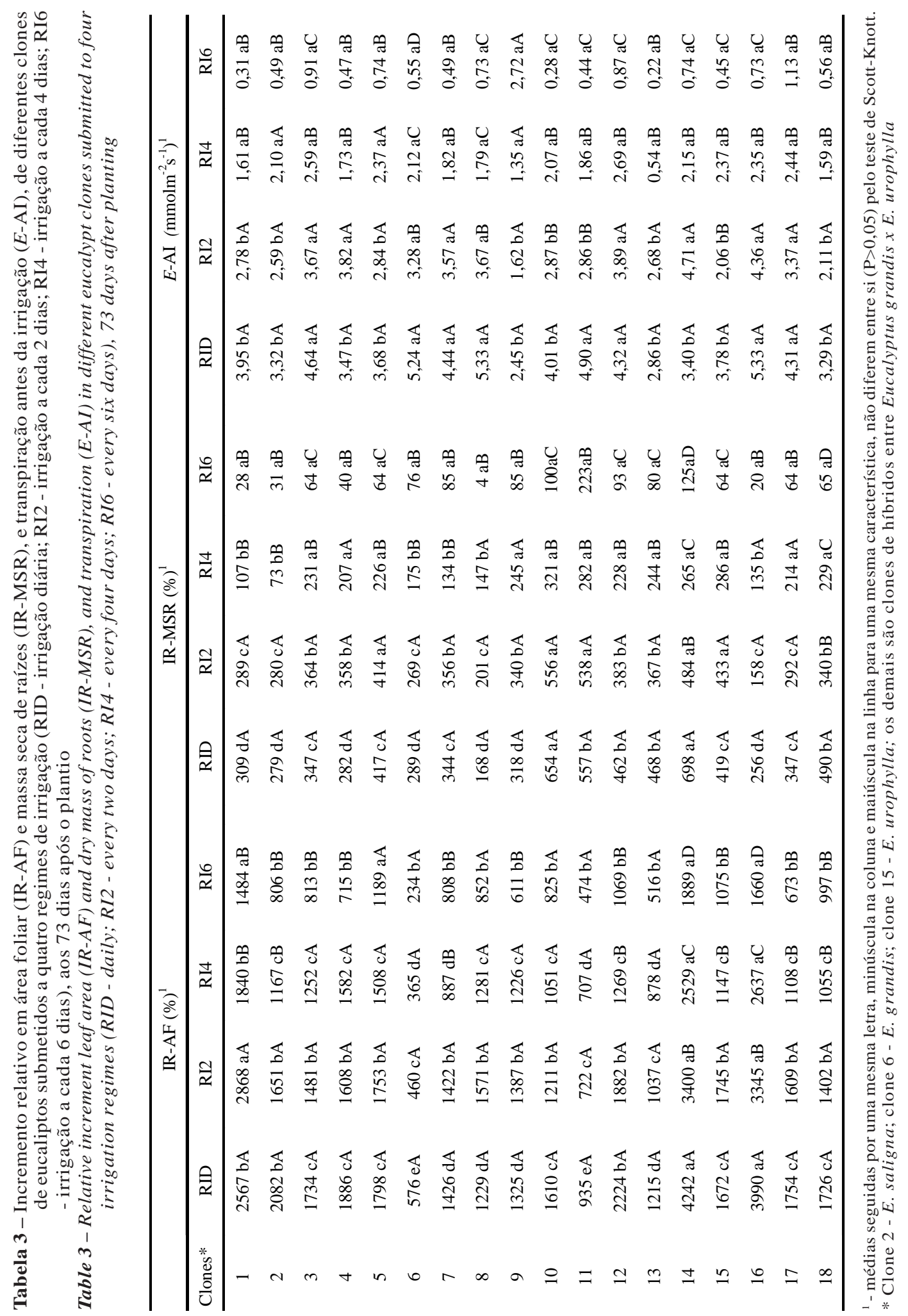


Diferenças expressivas ocorreram entre os materiais genéticos e entre os regimes hídricos para as características de crescimento (Figura 1) e fisiológicas (Figura 2). Na grande maioria dos casos, o regime de irrigação diária resultou em maior desempenho dos clones e a irrigação a cada seis dias em menor crescimento e, conseqüentemente, menor produção de massa seca. O crescimento em altura foi, proporcionalmente, menos afetado que o crescimento em diâmetro quando a disponibilidade hídrica diminuiu para as plantas. Reis et al. (2006), avaliando o comportamento de clones de híbridos de Eucalyptus grandis x E. urophylla e de $E$. camaldulensis $x E$. spp submetidos a dois regimes de irrigação no campo, observaram que o crescimento em altura, aos 38 meses de idade, não variou significativamente entre os tratamentos de irrigação, enquanto em diâmetro e volume foram significativamente superiores nas plantas do tratamento irrigado em relação ao nãoirrigado.

A produção de massa seca de raízes foi severamente prejudicada no regime de irrigação a cada seis dias (Figura 1), confirmando a condição desfavorável imposta por este regime ao desenvolvimento das plantas e, por conseguinte, não permitindo uma discriminação dos genótipos nesta condição.

Independentemente do regime hídrico, o genótipo 16 apresentou maiores valores nos parâmetros fisiológicos, ao passo que o clone 13 apresentou os valores mais baixos. Na média dos regimes hídricos, os maiores valores para $\varnothing_{\mathrm{f}}$ e para $A$, gs, E, foram observados no regime RID, enquanto os menores valores sempre foram observados no regime RI6. Sob condições não limitantes de água (RID), os estômatos se mantiveram abertos, portanto as plantas transpiraram livremente e assimilaram mais carbono resultando em maior crescimento e acúmulo de biomassa (Tabelas 1 e 2).

Comportamento diferenciado dos clones em relação aos regimes hídricos, quanto aos parâmetros fisiológicos foi observado apenas para a transpiração depois da irrigação (E-AI). Os regimes de irrigação diária (RID) e a cada dois dias (RI2) proporcionaram maiores valores nesta característica do que os regimes de irrigação a cada quatro e seis dias. No regime RID os clones 3, 6, 7, 8, 12, 16 e 17 apresentaram maiores valores de E-AI e no RI2, e os clones $14,16,12,4,3,8,7,17$ e 6 superaram os demais; já, nos regimes RI4 e RI6, os clones não diferenciaram entre si.
No geral, a taxa de fotossíntese líquida $(A)$ antes da irrigação (máximo estresse) diferiu pouco nos regimes RID, RI2 e RI4 de irrigação, sendo, contudo, relativamente inferior no RI6. Exceção é feita para o clone 9, que apresentou maiores valores de A no regime considerado mais restritivo às plantas. Desta forma, enquanto nos demais genótipos o fechamento de estômatos para economizar água provocou redução da assimilação de carbono no RI6, no clone 9 os estômatos se mantiveram abertos, proporcionando maior taxa de A que os outros. Desconsiderando-se o clone 9, o clone 17 teve a menor redução na taxa fotossintética no RI6, apresentando a maior A nesta condição. Após a irrigação, houve uma tendência de todos os clones, nos quatro regimes hídricos, apresentarem taxa de fotossíntese semelhante, evidenciando a recuperação do status hídrico dos mesmos.

Para $g s$ e $E$, todos os clones, à exceção do 9, apresentaram valores decrescentes nestas características com a redução da disponibilidade de água. Controle estomático da perda de água tem sido identificado como um dos primeiros eventos na planta em resposta ao déficit hídrico sob condições de campo, levando a redução da assimilação de carbono pelas folhas (CHAVES, 1991).

Além das diferenças apresentadas entre clones e entre regimes de irrigação, pode-se observar boa recuperação dos materiais genéticos no regime de irrigação menos freqüente após a irrigação. De uma forma geral, essa recuperação foi mais intensa para a taxa de transpiração $(E)$, do que para fotossíntese e condutância estomática. Kirschbaum (1987) observou recuperação de potencial hídrico foliar dentro de 7h, em E. pauciflora, e em fotossíntese um dia após a reirrigação. Essa recuperação das trocas gasosas logo após a reidratação é indicativo de tolerância ao estresse, assim como o fechamento parcial dos estômatos, observado através da diminuição nos valores de gs e $E$, mais rápida que a queda na fotossíntese. Resultados semelhantes foram, também, observados por Oliveira et al. (2002) com Bactris gasipaes (pupunheira). A taxa de fotossíntese, condutância estomática e a transpiração aumentaram nas plantas de todos os clones após a irrigação, concordando com os resultados de outros autores em estudos com plantas delaranja (MEDINA et al., 1999), Euterpeoleracea (CALBO e MORAES, 2000), pupunheira (OLIVEIRA et al., 2002) e Myracrodruon urundeuva (QUEIROZ et al., 2002). Somente nas plantas do clone 9 foi observado um comportamento contrário em que, no RI6, os valores dessas características foram maiores antes da irrigação. 

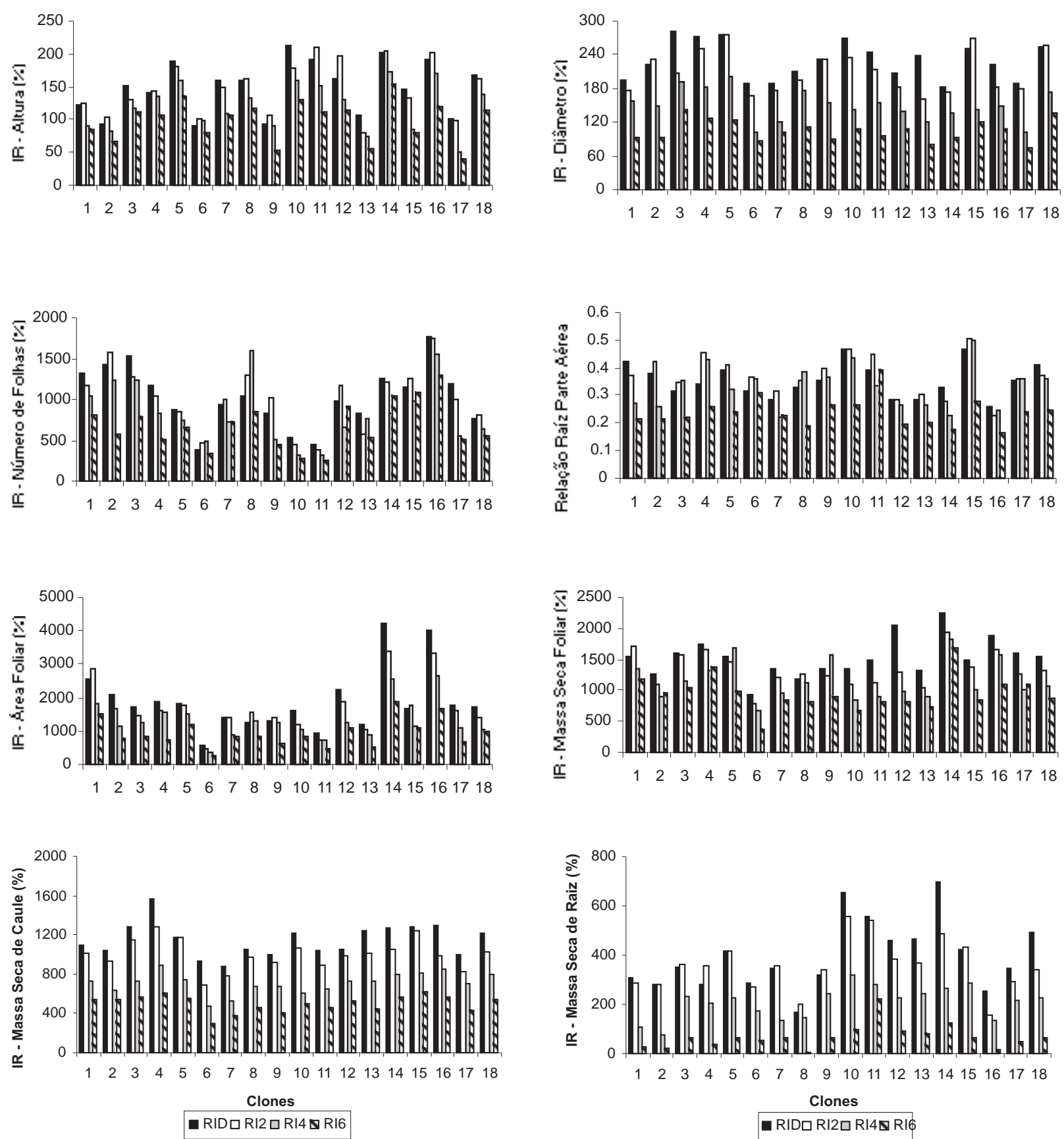

Figure 1 - Incremento relativo (IR, em \%) em altura, diâmetro do coleto, número de folhas, área foliar, massa seca de folhas, de caule e de raízes e razão raiz/parte aérea em diferentes clones de eucaliptos submetidos a quatro regimes de irrigação (RID - diário; RI2 - irrigação a cada 2 dias; RI4 - irrigação a cada 4 dias e; RI6 - irrigação a cada 6 dias), aos 73 dias após o plantio.

Figura 1 -Relative increment (IR, \%) in height, root collar diameter, number of leaves, leaf area, and dry mass of leaves, stem and roots and the root-shoot ratio in different eucalypt clones submitted to four irrigation regimes (RIDdaily; RI2 - every two days; RI4 - every four days; and RI6 - every six days), 73 days after planting. 

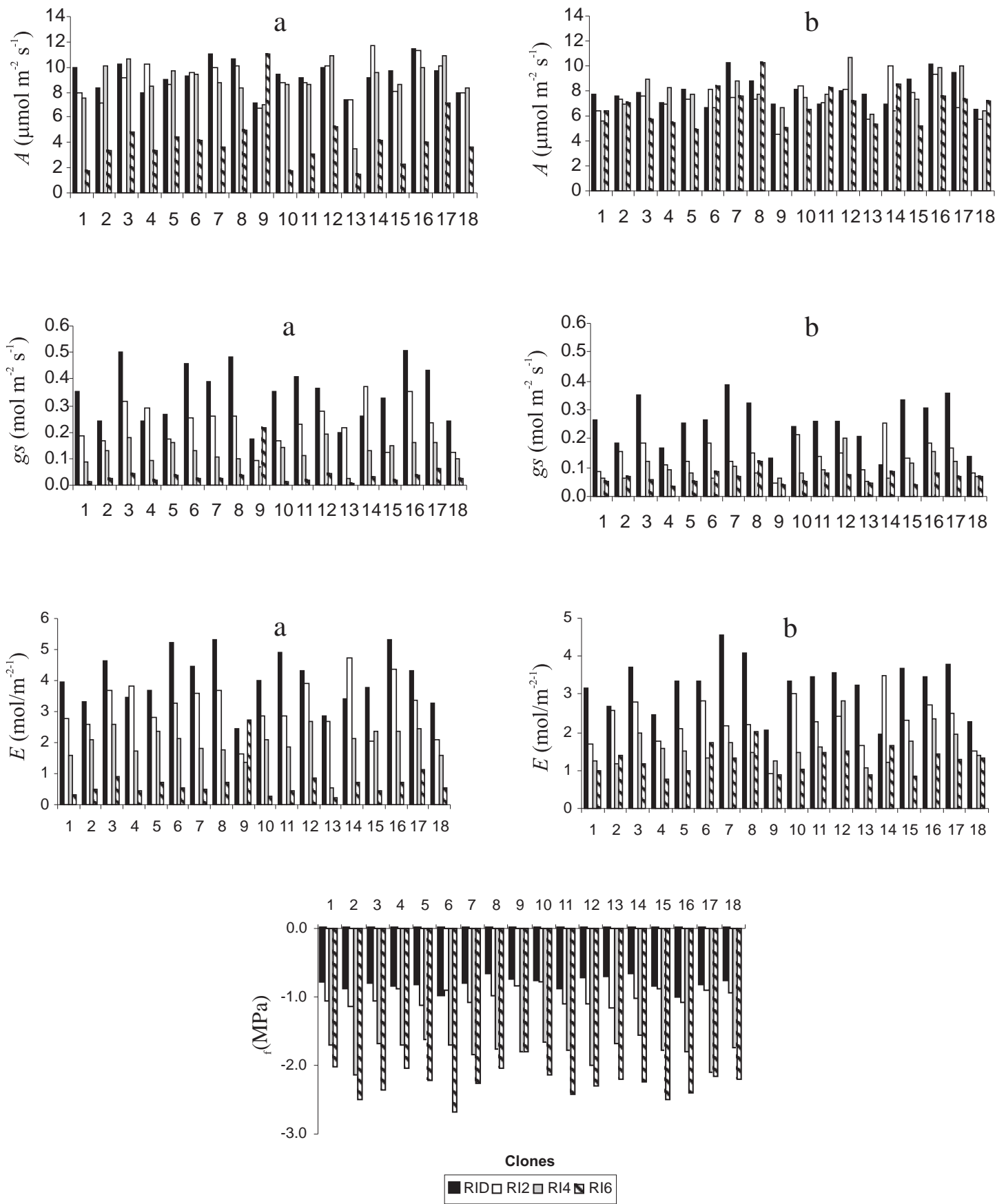

Figure 2 - Taxa líquida de fotossíntese $\left(A, \mu \mathrm{mol} \mathrm{m} \mathrm{m}^{-2} \mathrm{~s}^{-1}\right)$, condutância estomática (gs, $\left.\mathrm{mol} \mathrm{m}^{-2} \mathrm{~s}^{-1}\right)$ e transpiração ( $E, \mathrm{mmol} \mathrm{m}^{-2} \mathrm{~s}^{-1}$ ), antes (a) e após (b) a irrigação, e potencial hídrico foliar (Øf) em diferentes clones de eucaliptos submetidos a quatro regimes de irrigação (RID- diário; RI2 - irrigação a cada 2 dias; RI4 irrigação a cada 4 dias e; RI6 - irrigação a cada 6 dias).

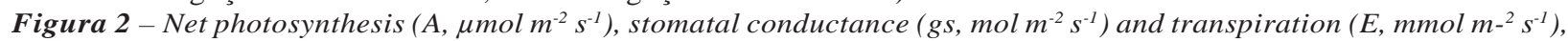
before (a) and after (b) irrigation, in different eucalypt clones submitted to four irrigation regimes (RID - daily; RI2 - every two days; RI4 - every four days; and RI6 - every six days). 
A condutância estomática ( $g s$ ) atingiu valores inferiores a $0,1 \mathrm{~mol} \mathrm{~m}^{-2} \mathrm{~s}^{-1}$ no regime RI4, ou seja, menos de $20 \%$ dos valores máximos em RID. Este resultado pode ser decorrente da baixa reserva hídrica no substrato. Chaves et al. (2002) salientam que em muitos experimentos tem sido observado que respostas estomáticas são mais estreitamente relacionadas ao conteúdo de água no solo do que ao status hídrico da planta, sugerindo que os estômatos respondem a sinais químicos (p. ex. ABA) produzido pela desidratação da raiz enquanto o status hídrico da folha se mantém constante. Paiva et al. (2005) encontraram resultados semelhantes em plantas de feijoeiro submetidas a diferentes regimes de irrigação. Essas mudanças na condutância estomática são de grande importância, pois genótipos que apresentam este controle quando submetidos a situações de falta de água podem tolerar ou resistir períodos variáveis nestas condições, sendo que além de controlar a falta de água controlam também a taxa de absorção de dióxido de carbono necessária para a fixação de $\mathrm{CO}_{2}$ durante a fotossíntese (CHAVES, 1991). Exceção é feita ao clone 9, em que a gs foi maior no RI6 comparativamente aos outros regimes de irrigação, o que sugere menor controle da transpiração sob condições de baixa disponibilidade hídrica.

\section{CONCLUSÕES}

Há considerável variabilidade e controle genético entre os clones de eucalipto quanto às características de crescimento e fisiológicas.

A redução na disponibilidade de água no substrato afetou negativamente a maioria dos caracteres avaliados.

A expectativa de progressos genéticos com a seleção na fase em que as plantas foram avaliadas é pequena.

Os clones 10, 14 e 16 merecem atenção especial em futuros trabalhos visando à seleção de genótipos de eucalipto tolerantes ao estresse hídrico, por terem apresentado melhor desempenho nas condições estudadas.

\section{AGRADECIMENTOS}

À Votorantim Celulose e Papel S.A., Unidade Florestal de Luiz Antônio, pelo suporte financeiro; à FAPESP, por possibilitar a aquisição do analisador a gás infravermelho (IRGA); à CAPES e ao CNPq, pelas bolsas concedidas.

\section{REFERÊNCIAS}

ARRIEL, E.F. Divergência genética em Cnidoscolus phyllacanthus (Mart.) Pax. Et K. Hoffm. 2004. 89f. Tese (Doutorado em Produção Vegetal) - Faculdade de Ciências Agrárias e Veterinárias, Universidade Estadual Paulista, Jaboticabal, 2004.

BRAY, E.A. Plant responses to water deficit. Trends in Plant Science, v.2, p.48-54, 1997.

CALBO, M.E.R.; MORAES, J.A.P.V. de. Efeitos da deficiência de água em plantas de Euterpe oleracea (açaí). Revista Brasileira de Botânica, v.23, p.225-230, 2000.

CALLISTER, A.N.; ARNDT, S.K.; ADAMS, M.A. Comparison of four methods for measuring osmotic potential of tree leaves. Physiologia Plantarum, v.127, p.383-392, 2006.

CAMBRAIA, J. Aspectos bioquímicos, celulares e fisiológicos dos estresses nutricionais em plantas. In: NOGUEIRA, R.J.M.C.; ARAÚJO, E. DE L.; WILLADINO, L.G.; CAVALCANTE, U.M.T.; (Ed.). Estresses ambientais: danos e benefícios em plantas. Recife: UFRPE, Imprensa Universitária, 2005. p.95-105.

CARVALHO, C.J.R. Respostas de plantas de Schizolobium amazonicum [S. parahyba var. amazonicum] e Schizolobium parahyba [Schizolobium parahybum] à deficiência hídrica. Revista Árvore, v.29, p.907-914, 2005.

CHAVES, J.H. et al. Seleção precoce de clones de eucalipto para ambientes com disponibilidade diferenciada de água no solo: relações hídricas de plantas em tubetes. Revista Árvore, v.28, n.3, p.333-341, 2004.

CHAVES, M.M. Effects of water deficits on carbon assimilation. Journal of

Experimental Botany, v.42, p.1-16, 1991.

CHAVES, M. M., PEREIRA, J. S.; MAROCO, J.; RPDRIGUES, M. L.; RICARDO, C. . P.; OSORIO, M. L.; CARVALHO, I,; FARIA, T.; PINHEIRO, C. How plants cope with water stress in the field. Photsynthesis and growth. Annals of Botany, v.89, p.907-916, 2002. 
CHAVES, M.M.; MAROCO, J.P.; PEREIRA, J.S. Understanding plant responses to drought from genes to the whole plant. Functional Plant Biology, v.30, p.239-264, 2003.

COSTA E SILVA, F.; SHVALEVA, A.; MAROCO, J.P.; ALMEIDA, M.H.; CHAVES, M.M.;

PEREIRA, J.S. Responses to water stress in two Eucalyptus globulus clones differing in drought tolerance. Tree Physiology, v.24, p.11651172, 2004.

CRUZ, C.D. Programa genes: Versão Windows; aplicativo computacional em genética e estatística. Viçosa: Editora Folha de Viçosa, 2001. 648p.

FLEXAS, J, ESCALONA, J.M.; MEDRANO, H. Water stress inducee different photosynthesis and electrón transport rate regulation in grapevine. Plant, Cell and

Environment, v.121, p.39-48, 1999.

FLEXAS, J.; BOTA, J.; ESCALONA, J.M.; SAMPOL, B.; MEDRANO, H. Effects of drought on photosynthesis in grapevines under field conditions. Functional Plant Biology, v.29, p.461-471, 2002.

GOMES, F.P. Curso de estatística experimental. 14. ed. Piracicaba: Ed. F P. Gomes, 2000. 477p.

KIRSCHBAUM, M.U.F. Water stress in Eucalyptus pauciflora: comparison of effects on stomatal conductance with effects on the mesophyll capacity for photosynthesis, and investigation of a possible involvement of photoinhibition. Planta, v.171, p.466-473, 1987.

MEDINA, C.L.; MACHADO, E.C.; GOMES, M.de M. de A. Condutância estomática, transpiração e fotossíntese em laranjeira 'Valência' sob deficiência hídrica. Revista Brasileira de Fisiologia Vegetal, v.11, p.29-34, 1999.

NEPOMUCENO, A.L.; NEUMAIER, N.; FARIAS, J.R.B.; OYA, T. Tolerância à seca em plantas: mecanismos fisiológicos e moleculares.

Biotecnologia Ciência \&

Desenvolvimento, n.23, p.12-18, 2001.

R. Árvore, Viçosa-MG, v.32, n.4, p.651-663, 2008
NGUGI, M. R.; HUNT, M. A.; DOLEY, D.; RYAN, P.; DART, P. Dry matter production and allocation in Eucalyptus cloeziana and Eucalyptus argophloia seedlings in response to soil water deficits. New Forests, v.26, p.187200, 2003.

NOGUEIRA, R.J.M.C.; MORAES, J.A.P.V.; BURITY, H.A.; BEZERRA NETO, E. Alterações na resistência à difusão de vapor das folhas e relações hídricas em aceroleiras submetidas à déficit de água. Revista Brasileira de Fisiologia Vegetal, v.13, p.75-87, 2001.

NOGUEIRA, R.J.M.C.; ALBUQUERQUE, M.B. de; SILVA, E.C. da. Aspectos ecofisiológicos da tolerância à seca em plantas da caatinga. In: NOGUEIRA, R.J.M.C.; ARAÚJO, E. DE L.; WILLADINO, L.G.; CAVALCANTE, U.M.T.; (Ed.). Estresses ambientais: danos e benefícios em plantas. Recife: UFRPE, Imprensa Universitária, 2005. p.22-31.

OLIVEIRA, M.A.J.; BOVI, M.L.A.; MACHADO, E.C.; GOMES, M.M.A.; HABERMANN, G.; RODRIGUES, J.D. Fotossíntese, condutância estomática e transpiração em pupunheira sob deficiência hídrica. Scientia Agrícola, Piracicaba, v.59, p.59-63, 2002.

OSÓRIO, J.; OSÓRIO, M.L.; CHAVES, M.M.; PEREIRA, J.S. Water deficits are more important in delaying growth than in changing patterns of carbon allocation in Eucalyptus globulus. Tree Physiology, v.18, p.363373, 1998.

PAIVA, A.S.; FERNANDES, E.J.; RODRIGUES, T.J.D.; TURCO, J.E.P. Condutância estomática em folhas de feijoeiro submetido a diferentes regimes de irrigação. Engenharia Agrícola, v.25, p.161-169, 2005.

PIMENTEL, C. Respostas fisiológicas à falta d’água: limitação difusiva ou metabólica? In: NOGUEIRA, R.J.M.C.; ARAÚJO, E. DE L.; WILLADINO, L.G.; CAVALCANTE, U.M.T.; (Ed.). Estresses ambientais: danos e benefícios em plantas. Recife: UFRPE, Imprensa Universitária, 2005. p.13-21.

\section{R. Arvore, Viçosa-MG, v.32, n.4, p.651-663, 2008}


PITA, P.; CAÑAS, I.; SORIA, F.; RUIZ, F., TOVAL, G. Use of physiological traits in tree breeding for improved yield in drought-prone environments. The case of Eucalyptus globulus. Investigación agraria: Sistemas y recursos forestales, v.14, p.383-393, 2005.

QUEIROZ, C.G.S.; GARCIA, Q.S.; LEMOS FILHO, J.P. Atividade fotossintética e peroxidação de lipídios de membrana em plantas de aroeira-do-sertão sob estresse hídrico e após reidratação. Brazilian Journal Plant Physiology, v.14, p.59-63, 2002.

REIS, G.G.; REIS, M.G.F.; FONTAN, I.C.I.; MONTE, M.A.; GOMES, N.A.; OLIVEIRA, C.H.R. Crescimento de raízes e da parte aérea de clones de híbridos de Eucalyptus grandis x Eucalyptus urophylla e de Eucalyptus camaldulensis x Eucalyptus spp submetidos a dois regimes de irrigação no campo. Revista Árvore, v. 30, p.921-931, 2006

REIS, G.G.; REIS, M.G.F.; MAESTRI, M. Crescimento e relações hídricas de mudas de Eucalyptus grandis e E. camaldulensis em tubetes sob três regimes de irrigação. Revista Árvore, v.12, n.2, p.183-195, 1988.

SCHOLANDER, P.F.; HAMMEL, H.T.; BRADSTRET, E.D.; HEMMINGSEN, E.A. Sap pressure in vascular plants. Science, v.148, p.339-346, 1965.

SEKI, M.; UMEZAWA, T.; URANO, K.; SHINOZAKI, K. Regulatory metabolic networks in drought stress responses. Current Opinion in Plant Biology, v.10, p.296:302, 2007.
SILVA, M.R. Caracterização morfológica, fisiológica e nutricional de mudas de Eucalyptus grandis Hill ex Maiden submetidas a diferentes níveis de estresse hídrico durante a fase de rustificação. 1998. 105f. Dissertação (Mestrado e Silvicultura) - Universidade do Federal do Paraná, Curitiba, 1998.

SOUZA, M.J.H.; RIBEIRO, A.; LEITE, H.G.; LEITE, F.P.; MINUZZI, R.B. Disponibilidade hídrica do solo e produtividade do eucalipto em três regiões da Bacia do Rio Doce. Revista Árvore, v.30, p.399-410, 2006.

STAPE, J.L.; BINKLEY, D.; RYAN, M.G. Eucalyptus production and the supply, use and efficiency of use of water, light and nitrogen across a geographic gradient in Brazil. Forest Ecology and Management, v.193, p.17-31, 2004.

TARDIEU, F.; SIMMONNEAU, T. Variability among species of stomatal control under fluctuating soil water status and evaporative demand: modeling isohydric and anisohydric behaviours. Journal of Experimental Botany, v. 49, p.419-432, 1998.

TAYLOR, I.B.; BURBIDGE, A.; THOMPSON, A.J. Control of abscisic acid synthesis. Journal of Experimental Botany, v.51, p.1563-1575, 2000.

VENCOVSKY, R. Herança quantitativa. In: PATERNIANI, E. Melhoramento e produção de milho. Piracicaba: Fundação Cargill, 1987. p.137-214.

WRIGHT, I.J.; GROOM, P.K.; LAMONT, B.B.; POOT, P.; PRIOR, L.A.; REICH, P.B.; SCHULZE, ED.; VENEKLAAS, E.J.; WESTOBY, M. Leaf trait relationships in Australian plant species.

Functional Plant Biology, v.31, p.551-558, 2004. 